\title{
An Inquiry into Impediments of Education for All with Focus Orphaned Learners in Kiganjo Zone in Kenya
}

\author{
Antony Ndung'u Njihia \\ Mount Kenya University, Kenya
}

\section{Doi:10.5901/jesr.2014.v4n1p167}

\begin{abstract}
Occurrence of orphans has been in every society since time immemorial. In some societies, they have been treated like outcasts while others they have been treated well. In Kiganjo zone, Gatundu South District-Kenya there are orphans learners. Their parents may have died through diseases like HIVIAIDS, cancer, accidents through ethnic animosity or war, leaves them improperly attended in many areas including education matters. Mostly these orphans are left at the care of their grandparents who are old and sometimes poor. These learners need proper care, education and guidance and counseling. This should be in line with children's Act 2001which identifies the rights to education value, assurance of shelter and allowance to participate fully in the society. In January 2003 education was declared free in primary schools and affordable secondary education in January 2008 by the government of Kenya. However, to the best of my knowledge no research have been conducted to find out the number of orphan learners umber of teachers trained in guidance and counseling, number of teachers trained in special needs education, behavioural changes in orphan learners, economic wellbeing of orphan learners, general educational performances of orphan learners and attitudes of learners and teachers towards orphan learners in Kiganjo zone.
\end{abstract}

Keywords: Education, Orphans, Access, Learners, Challenges

\section{Introduction}

The history of orphans is as old as history; children have been left without both parents since time immemorial. All over the world these orphans' children have suffered the consequences related to the so called cycles of poverty, dependency, welfare problems, learning difficulty, delinquency problems and maturation vocational and career problems. (Jerome Hellmuth 1999).

Educational challenges are many and of different magnitudes. Some come as a result of hereditary factors and other through environmental factors. The hereditary factors may affect education of a learner physically, psychologically, mentally and emotionally. This could come in form of physical disabilities, mental retardation or through health problems. Environmental factors may include poverty, war, diseases and natural calamity like drought and earthquakes. Environmental factors may lead to learners living in the following categories-street children, workers and others learners affected by such hereditary and environmental factors will not be able to continue with education smoothly like the other learners.

The psychological effects of orphan learners lead to a strong sense of insecurity and instability and think that adults are not to be trusted. In school, these learners are rejected and teased by classmates and friends. They are also teased because of torn school uniform, inability to bring lunch boxes etc. (mokgadi kekae- moletsane 2009).

The love of parents has potential serious and long-term negative consequences for children as it could put them at risk of attaining less than favorable schooling outcomes as a result of being orphaned. Low education attainment is associated with a number of negative life course outcomes such as lower-social economic status and worse health outcomes. However, previous studies that have been done on the subject have returned mixed results with some showing significant orphan disadvantage while others have shown little or no significant difference in schooling outcomes for orphans as compared to non-orphans (Ainsworth Beaagle and Koda Zambia, 2007).

Ugandans observe that children who suffer the death of their parents are denied parental protection, care and educational service. These children are burdened by sudden responsibilities and/or forced to tend for themselves making them less visible in their communities. They find themselves victims of exploitation. Being an orphan and losing direct parental care often puts an end to their educational opportunities. Les than $10 \%$ of the orphaned children receive public support and services (UNICEF/UNAIDS 2005) a core study in Western Uganda.

Resources enable a learner to have a smooth learning process increasing efficiency and performance. In Kenya 
the government through the Ministry of Education (MOE) provides for funds for learning institutions, pay teachers and learning materials for all learners. There is no special provision set aside to cater for orphan learners especially in the part of the funds and learning materials as they should be treated as special needs learners. There is the government kitty called cash transfer OVC (Orphans and Vulnerable Children) which intends to facilitate the wellbeing of these orphans. Before a learner is identified for the cash handout, certain selection criterion is followed as below:-

\begin{tabular}{|l|l|l|}
\hline Selection Criteria & Comments & Weight \\
\hline Orphan or vulnerable child & & \\
\hline Child-headed households & Should be given priority & \\
\hline Number of people in the household & To capture per capita income & \\
\hline Age-limit: 14 & & \\
\hline Age of care-taker & Particularly to capture cases where the care-giver is a grandparent & \\
\hline Marital status/single parenthood & Supplementary & \\
\hline In-school/out-of-school status & Supplementary & \\
\hline Not in any way related to committee members & & \\
\hline Long-term disability/lilness & & \\
\hline
\end{tabular}

\section{Research Methodology}

The researcher used descriptive survey method. It adopted an exploratory approach in investigating educational challenges facing orphan learners with an effort to identifying the challenges, their extent in affecting education of the learners and justifiable solutions towards these challenges, descriptive survey designs are used in preliminary and exploratory studies (Luck and Ruben 1992) to allow the researcher to gather information, summarize, present and interpret for the purpose of clarification (Orodho, 2002). The descriptive survey design was intended to produce statistical information about aspects of education that interest policy makers and educators. By involving broad categories of stakeholders, the study fitted within the cross-sectional sub-types of descriptive survey study design.

The target population were teachers and learners in public primary schools in Kiganjo Zone, Gatundu South District. There were twenty schools in Kiganjo zone. The total number of learners and teachers were seven thousand and eighty and two hundred and forty respectively. The sampling units were five schools in the zone. Those sampled schools had a total of two thousand four hundred and sixty learners including orphans and sixty nine teachers.

The instruments the researcher used were questionnaires, observation guides and interview guide. The researcher will use the three instruments in order to get maximum information from the respondents. The questionnaire enabled the researcher to get answers from respondents which they cannot answer face to face. The questionnaire was divided into three sections. The first section will deal with Yes/No responses. The second section involved close-ended responses. The researcher observed the orphans in their natural situations in schools without them noticing the endeavor. The researcher interviewed sampled teachers and orphans from the sampled schools. The interview was done through face-to-face method.

The researcher collected data in the five sampled schools. The collection of the data involved both qualitative and quantitative techniques. Qualitative data involving identifying behavioral changes was researched on through thematic analysis. The other information and data was analyzed using quantitative technique. The researcher coded the data mainly through direct counting from the questionnaire and tally method. After entering the data into their different codes, statistical analysis was done through tabular and chart form. These included graphs like the pie charts, bar graphs and tables. Then inferences were made, recommendations and conclusions made.

\section{Theoretical Support}

The Classical Liberal Theory (Roussean 1712 - 1778) fits well with research study about educational challenges facing orphan learners. The theory asserts that each person is born with a given amount of capacity which to a large extent is inherited and cannot be substantially changed. Thus educational systems should be designed so as to remove barriers of any nature (economic, gender, geographic) that prevent bright students from lower economic backgrounds from taking advantages of inborn talents which accelerate them to social promotion. Liberal progrevisits like Horance Mann termed as "the great Equalizer" Main instrument which would enhance life chances of those born into humble circumstances. The theory demands for further going through education at primary and secondary level to which access would be determined on the basis of individual's merit and not on social background (Orodho, J.A. 2008). 
The theory fits well with education of orphan learners, when their parents die; very many difficulties may arise jeopardizing their education accessibility. This may be due to loss of income from their late parents, behavioral changes up to stigmatization as a result of the death of the parents. The theory put it clearly that all factors put constant to facilitate education for all learners. The present government of National Unity in Kenya has tried to confirm with the classical liberal theory by continued offering of Free Primary Education (FPE) and affordable of secondary education of all Kenyans regardless of gender, tribe or even social background of the learners.

\section{Training Teachers of Guidance and Counselling and Special Needs Education}

Wills, 2009 states that all community agencies should be alerted to their opportunities to provide support to the sick in their midst and help people with HIV IAIDS and their dependants. Counseling materials and message will need to be particularly relevant to specific target groups whether these are families, women, sex workers or youth. As former President of South Africa Nelson Mandela stated in his closing address to XIII World AIDS conference. The challenge is to move from rhetoric to action and action at an unprecedented intensity and scale. There is need to focus on what we know works. We need to break the silence, banish stigma and discrimination and ensure inclusiveness within the struggle against AIDS.

Theresa S. et al 2009 states that despite the strong desire of most of the former child soldiers to pursue educational opportunities, significant structural barriers existed. Concerns over paying for school fees and materials were voiced in 55 percent of key informant interviewees. When asked why she was not in school, an older female adolescent from Pujehun simple stated, "there is no money to pay my fees", caregivers shred this concern. For instance, a caregiver in Kono participating in focus group emphasized, paying my children's school fees is a problem, as I do not have anybody helping me. My husband .... is dead. One of my children could not complete his fifth form because of lack of money." Of the 31 youth interviewed, 10 (32 percent) reported that they had received school fees support from NGO's 15 (48 percent) reported receiving school related items including books, uniforms and school bags but not school fees, and 6 (19 percent) said that NGO assistance was trivial (i.e. soap and two packets of biscuits) or that they have ever received any help, while those who were receiving school-related assistance from NGO's were generally grateful for it they still expressed concerns because the amount offered was not always enough to cover the various cost of schooling. For example, an older male adolescent from Kono remarked, "For now things seem to be better. But my only problem is my education, as my parents are very poor".

\section{Behavioural Changes in Orphans}

Theresa et al, (2009) states that the aftermath in Sierra Leone war, there was evidence of mental health problems that may hinder educational progress. Many of our participants reported persistent psychological distress or trauma relating to activities and experiences during the war. Problems discussed by children interviewed included nightmares, intense sadness, and recurring intrusive thoughts and images centering on the violence that they participated in or saw during the war. The Psychological challenges faced by some children resemble hallmark symptoms of PSTD and other traumatic stress reactions. Current Psychological distress or worries were mentioned spontaneously in 11 of the 31 (32 percent) former child soldiers, key informant interviews as well as by youth participants in focus groups. For example:

1. "My mother was killed (in front of me), and I was left crying and confused" (younger female adolescent focus group participant, Kono).

2. "When I remember the war I become worried. I think about the way (my sister) was raped and killed" (younger female adolescent focus group participant Bombali).

3. "Whenever I think of my father and mother I feel sad and resort to doing things".

4. "Education came to a stand still. The RUF killed people and therefore created so much fear in (us) and made think of my parents all the time. I have suffered from mental stress since then" (younger adolescent female interviewee, Kono).

5. "Even among my friends I become violent and get annoyed over trivial issues" (older adolescent male interviewee, Bo).

All learning institutions have a responsibility to address HIV and AIDS through education by developing skills and values and changing attitudes to promote positive behaviour that combat scourge. Curriculum that is sensitive to cultural and religious beliefs and is appropriate to age, gender, language, special needs and context on HIV and AIDS shall form part of the education for all learners at all levels. 
Local communities, religious group and leaders, parents, caregivers and guardians will be mobilized to support and ensure success of HIV and AIDS prevention and control programme within learning institution and in the home.

Teacher education curriculum (pre-service and in service) must prepare educators to respond to HIV and AIDS within their own lives and as professionals to build positive attitudes and skills for HIV and AIDS prevention and control among learners. This is according to education sector policy on HIV and AIDS, Republic of Kenya, May 2006.

\section{Challenges of Orphan Learners}

Hellmuth, (1967) states that the disadvantages child has achieved a pre-eminence as a target for social action programs. This has apparently derived from the conviction that there are long range individual and social consequences of life's early privation. These consequences relate to the so called cycles of poverty, dependence, welfare problems, learning difficulty, delinquency and maturational, vocational and career problems. It would seem that these cycles are inadvertently being perpetuated from generation to generation and it is this reason that they are such grave concern both community and national levels. When we speak of the disadvantaged child we refer to a child deprived of the same opportunity for health growth and development is available to the vast majority of the other members of the large society in which he lives. We postulate that an additional factor which interferes with the disadvantaged child's development of controls in his over exposure to some of the frightening behaviour patterns of people around him.

Hellmuth J, (1978) states that the largest source in school achievement were found to be associated with family background, social economic status and race. Initial mental ability of the accounts for more of the individual differences is subsequent school performance than any other single variable. It should be a cause of concern that wealth, health and medical might of America are still incapable of meeting the needs of its people. In Boston, one of the great health centers of the worlds there are simply not enough resources to meet the comprehensive health needs of head start children particularly in the dental and mental health areas.

Hellmuth, (1980) states that impoverished children were fully capable of such learning and demonstrated this potential when guided in appropriate learning experience. The fact that most such children did not perform well in schools was mainly a function of negative attitudes and low expectations among professional, staff and especially of instructional methods and materials ill-suited to their development needs. The observed academic deficiencies of such children called not for special programs of compensatory education but simply for good teaching and this necessary implied the adaptation of school methods and materials and effective climates to the different needs of learners from impoverished background. In Rwanda's estimated 100,000 child headed households, orphan often forgo or delay school to earn enough money for food and shelter. "These children faced many problems some years ago in this country and they have wounds of minds, wounds of heart," Mr. Gisanura said (Nicole, 2009).

Since the genocide, organizations and orphanages have emerged to assist the country's estimated 1.35 million orphans and vulnerable children, one of the largest orphan populations in the world. But less than 1 percent of these children have received the medical, educational, social and mentioned support they need, according to the 2007 report by the Rwanda government.

If you saw the smile on the faces of orphaned twin brothers Saidi and Rama Khamisi, you will be inspired by their determination. They have severe deformities including knock knees, deformed elbows, orched backs, twisted spinal chords and swollen heads. Four years ago Saidi and Roma almost lost hope when their mother also disabled, died suddenly. Their mother, who lived with them at a shanty in Likoni, fell sick one afternoon and died before they could get her to the hospital.Her death worsened their bad health and they became skinny, emaciated, sickly and in dire need of special attention. The twins now aged eight, learned to live the hard way with whatever was offered by their mother's friend and landlord.

The twins say they were born disabled although psychotherapist at the association of the physically Disabled of Kenya (APDK) clinic say rickets may be to blame, when the Association took them in for rehabilitation early this year, the twins' faces lit up once more. This is according to the standard Newspaper, October 19, 2008.

Jerome in his research of 1999 highlights the disadvantage child like orphans general deprivations. This includes health and development problems. However, the previous studies have not mentioned the educational challenges which might interfere with the learning of these orphans. To fill this gap the researcher deeply investigated these challenges at school like, the attitudes of other learners and teachers towards orphaned learners, the factors which are affecting the performance of the orphans in school. The researcher will also establish who takes care of these orphans at home. The researcher will also do an in depth investigation on the number of teachers trained in special needs education and in guidance and counseling and compute a percentage which can give the overall picture in Gatundu South District, Kiambu 
county and Kenya in general.

\section{Data Analysis and Discussion}

The results given are a product of data analysed. The study findings are represented in form of tables, charts and graphs together with validation of results. It would be followed by drawing inferences from the collected facts.

Table 4.1: Number of orphan learners in Kiganjo Zone

\begin{tabular}{|l|c|c|c|}
\hline \multicolumn{1}{|c|}{ School } & Enrollment & Number of orphans & \% per school \\
\hline Gachika & 427 & 13 & 3 \\
\hline Gathiru & 397 & 9 & 2.3 \\
\hline Gicheru & 326 & 9 & 2.7 \\
\hline Kiganjo & 710 & 19 & 2.6 \\
\hline Ucekeini & 600 & 10 & 1.6 \\
\hline TOTAL & 2460 & 60 & 2.4 \\
\hline
\end{tabular}

Source: Primary data 2011

Table 4.1 Indicates that the average occurrence of orphan learners in the zone is $2.4 \%$. The number appears small which might be ignored by many people including stakeholders like teachers and other educationists. If these orphan learners are ignored, it means that they will suffer silently. These sufferings cause challenges in education. Educations challenges will lead to low academic performance or the learner may drop out of school.

Table 4.2: Number of trained teachers in special needs education in kiganjo zone

\begin{tabular}{|l|c|c|c|}
\hline \multicolumn{1}{|c|}{ School } & Total number of teachers & Trained in Special Needs Education & Percentage (\%) \\
\hline Gachika & 15 & - & 0 \\
\hline Gathiru & 9 & 1 & 11 \\
\hline Gicheru & 9 & - & 0 \\
\hline Kiganjo & 21 & 1 & 5 \\
\hline Ucekeini & 15 & 2 & 13.3 \\
\hline TOTAL & 69 & 4 & 5.8 \\
\hline
\end{tabular}

Source: Primary data 2011

Table 4.2 reveals that the percentage of teachers in Kiganjo Zone trained in Special Needs education is $5.8 \%$ on average. This is a very low number comparing with the many cases of special attention required to be given to learners especially orphans. It is also noted that some schools totally lacks teachers trained in special needs education. The estimated number of learners with special needs in any primary school in Kenya is $10 \%$. This percentage includes orphan learners. This means that the orphans in these schools are not properly handled meaning they have challenges in their education. 
Figure 4.1: Number of trained teachers in Special Needs Education Compared with actual teachers per school.

Source: Based on table 4.2

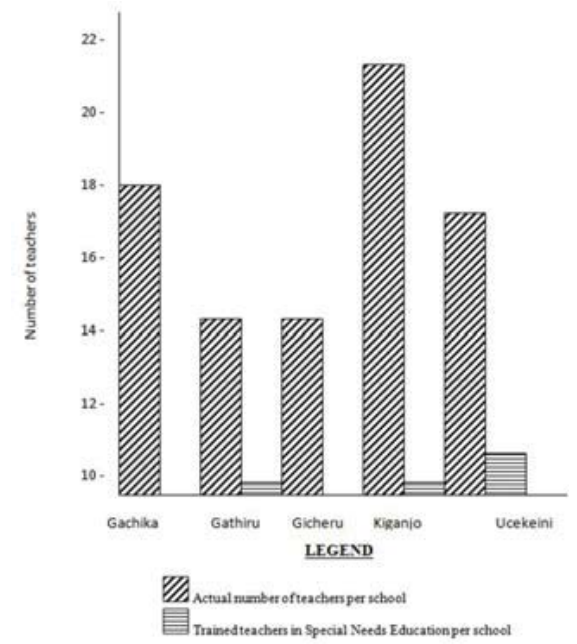

Table 4.3: Number of trained teachers in guidance and counseling in Kiganjo Zone

\begin{tabular}{|l|c|c|c|}
\hline \multicolumn{1}{|c|}{ School } & Total number of teachers & Trained in guidance and counseling & Percentage (\%) \\
\hline Gachika & 15 & 1 & $6.7 \%$ \\
\hline Gathiru & 9 & 1 & 11 \\
\hline Gicheru & 9 & 1 & 11 \\
\hline Kiganjo & 21 & 2 & 9.5 \\
\hline Ucekeini & 15 & 2 & 13.3 \\
\hline TOTAL & 69 & 7 & 10.1 \\
\hline
\end{tabular}

Source: Primary data 2011

Table 4.3 reveals that in all the schools there is at least a teacher trained in guidance and counseling. It revealed that an approximate $10 \%$ of the total number of teachers in the zone had trained in guidance and counseling. Although it is burdensome, serious cases needing guiding and counseling can be handled in all the schools.

Table 4.4: Number of orphan learners taken care by grand parents

\begin{tabular}{|l|c|c|c|}
\hline \multicolumn{1}{|c|}{ School } & Number of orphans & Number taken care by grand parents & Percentage (\%) \\
\hline Gachika & 13 & 8 & 61.5 \\
\hline Gathiru & 9 & 5 & 55.6 \\
\hline Gicheru & 9 & 8 & 88.9 \\
\hline Kiganjo & 19 & 12 & 63.2 \\
\hline Ucekeini & 10 & 7 & 70.0 \\
\hline TOTAL & 60 & 40 & 66.7 \\
\hline
\end{tabular}

Source: Primary data 2011

Table 4.4 reveals that many orphan learners are taken care of by their grandparents. This is so because on average $66.7 \%$ is a large number. The case of Gicheru primary school reveals nearly all orphans are taken care of by grandparents. That is $88.9 \%$. These grandparents may be too old to manage all educational needs of the orphans. Such educational needs like close supervision of learner academic achievements, completion of school homework, and maintenance of proper academic records. These shortcomings pose serious educational challenges to the orphans. 
Figure 4.2: Pie chart showing by percentages and degrees the number of orphan learners taken care by grandparents.

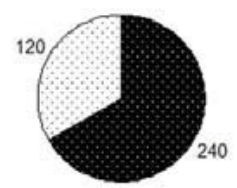

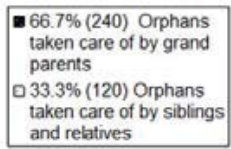

LEGEND

Part reptesenting orphans taken care of by Grandpatent

Part representing orphans taken care by others

Source: Based on table 4.4, page 44

Table 4.5: Number of orphan learners taken care by siblings

\begin{tabular}{|l|c|c|c|}
\hline \multicolumn{1}{|c|}{ School } & Number of orphans & Number taken care by siblings & Percentage (\%) \\
\hline Gachika & 13 & 5 & 38 \\
\hline Gathiru & 9 & 2 & 22 \\
\hline Gicheru & 9 & - & 0 \\
\hline Kiganjo & 19 & 4 & 21 \\
\hline Ucekeini & 10 & - & 0 \\
\hline TOTAL & 60 & 11 & 18 \\
\hline
\end{tabular}

Source: Primary data 2011

Table 4.5 reveals that a notable percentage of $18 \%$ of orphan learners is taken care by siblings. This makes families headed by children- leaders. The children leading the family may find it difficult to cover all the education needs of the rest of the family members. The children leader may find it difficult to cater for clothes, food, and health issues even before attending to educational needs. The leader organizes for school routine for the other children in the family. This might lead to serious educational challenges in the orphans.

Figure 4.3: Pie chart showing by percentage and degrees the number of orphan learners taken care by siblings.

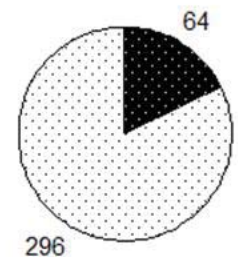

- $18 \%(64)$ orphans
taken care by
siblings
$\square 82 \%(296)$ orphans
taken care by
relatives

Source: Based on table 4.5, page 44

Figure 4.4: Pie chart showing percentages and degrees of orphans taken care by grandparents, siblings and relatives.

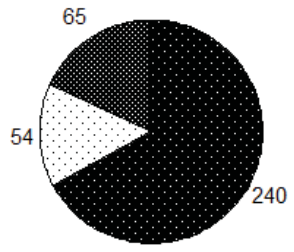

LEGEND

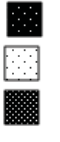

Part representing orphans taken care of by Grandparents

Part representing orphans taken care by relatives

Part representing orphans cared by siblings

Source: Based on tables 4.4, 4.5 and 4.6, pages 42,45 and 47 
Table 4.6: Number of orphan learners who are taken care by relatives apart from siblings

\begin{tabular}{|l|c|c|c|}
\hline \multicolumn{1}{|c|}{ School } & Number of orphan learners & Number taken care by relatives & Percentages (\%) \\
\hline Gachika & 13 & - & 0 \\
\hline Gathiru & 9 & 2 & 22 \\
\hline Gicheru & 9 & 1 & 11 \\
\hline Kiganjo & 19 & 3 & 16 \\
\hline Ucekeini & 10 & 3 & 33 \\
\hline TOTAL & 60 & 9 & 15 \\
\hline
\end{tabular}

Source: Primary data 2011

Table 4.6 reveals that a $15 \%$ of orphans are taken care of by relatives. This learner has to learn to live in a new environment. In the new environment, the learner must adapt to the moral and spiritual behaviour of relatives. The learner may be overburdened. Such burdens includes working in the shambas for many hours, attending home cores without the regard of educational matters, and getting insufficient food and health care. This could seriously affect their educational advancement especially where monetary matters are accounted.

Figure 4.5: Pie chart showing by percentage and degrees the number of orphans taken care by relatives.

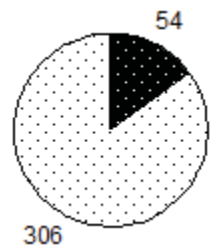

$15 \%(54)$ orphans taken
care by relatives
$85 \%$ ( 306 ) orphans taken
care by siblings and
grandparents

Source: Based on table 4.6 page 47

Table 4.7: Number of orphans learners whose economic status worsened after death of their parents

\begin{tabular}{|l|c|c|c|}
\hline \multicolumn{1}{|c|}{ School } & Number of orphans & Number whose economy worsened & Percentage (\%) \\
\hline Gachika & 13 & 9 & 69 \\
\hline Gathiru & 9 & 6 & 67 \\
\hline Gicheru & 9 & 4 & 44 \\
\hline Kiganjo & 19 & 19 & 100 \\
\hline Ucekeini & 10 & 9 & 90 \\
\hline TOTAL & 60 & 47 & 78 \\
\hline
\end{tabular}

Source: Primary data 2011

Table 4.7 reveals that many of the orphan learners economic wellbeing deteriorated after their parents died. In such a school like Kiganjo Primary School, all orphans (10\%) economic wellbeing worsened when their parents died. These learners will need uniform, food and shelter in order to achieve in education. A source for funds must be available. In this case, funds available are negligible or none. This could cause handicaps in maintaining these learners in school even in this era of Free Primary Education and affordable Secondary Education meaning it would create challenges in their education.

Figure 4.6: Bar graph showing percentage number of orphan learners whose economic wellbeing worsened. 
Source: Based on table 4.7

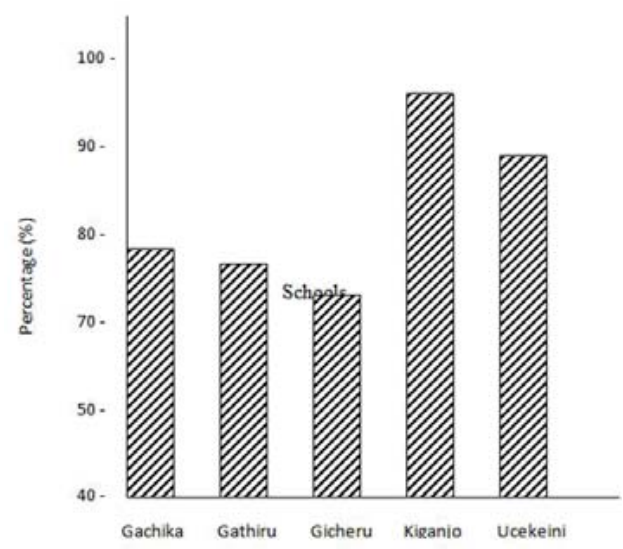

Table 4.8: Showing the attitudes of other learners towards orphan learners

\begin{tabular}{|l|c|c|}
\hline \multicolumn{1}{|c|}{ Response } & Respondents & Percentage \% \\
\hline Excellent & - & 0 \\
\hline Good & 8 & 53 \\
\hline Fair & 4 & 27 \\
\hline Bad & 13 & 20 \\
\hline TOTAL & 15 & 100 \\
\hline
\end{tabular}

Table 4.8 reveals that $53 \%$ of other learners in learners in the schools portray good attitudes towards orphans. $27 \%$ fair attitudes at the lowest $20 \%$ as bad attitudes. $47 \%$ raging from fair to bad attitudes would mean behaviours like discrimination, hatred and uncooperation towards the orphan learners. This further shows the learning environment is not conducive hence treating education challenges in orphan learners' attitudes.

Figure 4.7: Pie chart showing respondents percentage who state attitudes are excellent good, fair and bad towards orphan learners from other learners.
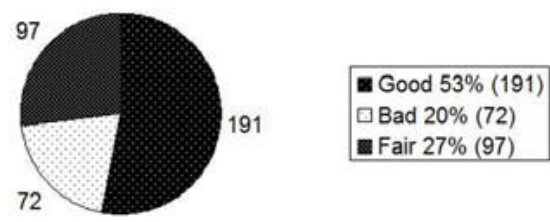

Source: Based on table 4.8, page 50

Table 4.9: Showing how teachers support the learning of orphan learners

\begin{tabular}{|l|c|c|}
\hline \multicolumn{1}{|c|}{ Responses } & Respondents & Percentages (\%) \\
\hline Supports & 10 & 67 \\
\hline Does not support & 5 & 33 \\
\hline TOTAL & 15 & 100 \\
\hline
\end{tabular}

Source: Primary data 2011

Table 4.9 reveals that $67 \%$ of the teachers in the zone support learning of orphan learners while $33 \%$ do not support the learning of the orphans. The $67 \%$ is commendable and may be improved to a hundred if proper awareness is given to teachers supporting learning of the orphans. One possible explanation is that teachers undergo a general teaching course where child psychology is taught. It is their duty to support learners regardless of their status in life. These $33 \%$ of 
teachers may not help these learners when in need. It implies that a third of teachers may hate, humiliate or cause sufferings to orphan learners. This is good revelations. The 33\% who does not support could create educational challenges.

Figure 4.8: Pie chart showing percentage of respondent who say teachers support learning of orphans or not.

Source: Based on table 4.9, page 52
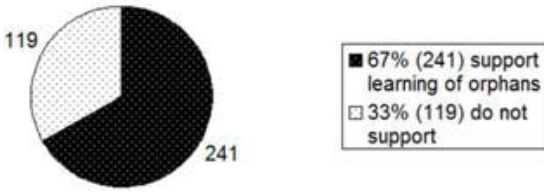

Table 4.10: Showing whether the number of orphan learners were increasing or decreasing in the zone

Source: Primary data 2011

\begin{tabular}{|c|c|c|}
\hline Class & Number of orphans & Percentage (\%) \\
\hline 1 & 10 & 17 \\
\hline 2 & 6 & 10 \\
\hline 3 & 10 & 17 \\
\hline 4 & 7 & 12 \\
\hline 5 & 8 & 13 \\
\hline 6 & 6 & 10 \\
\hline 7 & 8 & 13 \\
\hline 8 & 5 & 8 \\
\hline TOTAL & 60 & 100 \\
\hline
\end{tabular}

Table 4.10 reveals that the number of orphan learners were increasing as class one had $17 \%$, class two has $10 \%$ and class three $17 \%$ and class eight $8 \%$, class seven $13 \%$ and class six $10 \%$. The percentage of orphans in the lower classes from standard one to standard four is $56 \%$ and for the rest of classes is $44 \%$. An increased number of orphans also means an increased number of deaths of parents. It also implied ignorance and irresponsibility on the part of parents in attempts to stop or evade the causes of deaths. This means there will be an increased population of orphans in the community in future. It also means that in future, learners will be having educational challenges.

Figure 4.9: Bar graph showing number of orphans per class in the zone indicating whether there is an increase or a decrease of them.

Source: Based on table 4.10, page 54

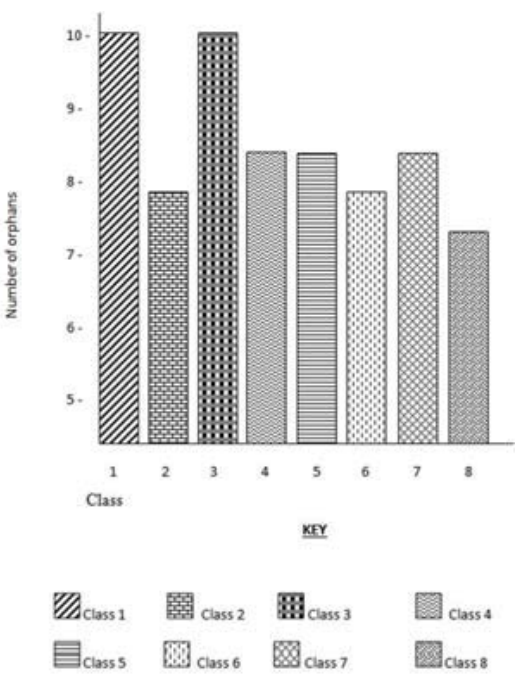


Table 4.11: Showing behavioural changes in orphans learners

\begin{tabular}{|cl|c|c|c|}
\hline \multicolumn{1}{|c|}{ Responses } & Respondents & Out of & Percentage (\%) \\
\hline 1. & Orphan learners always absent minded in class. & 10 & 15 & 67 \\
2. & Some orphan learners practice truancy. & 8 & 15 & 53 \\
3. & Some orphan learners steal from others. & 9 & 15 & 60 \\
4. & Some learners' academic performance keeps on getting lower. & 8 & 15 & 53 \\
5. & Some orphan learners are dirty. & 10 & 15 & 67 \\
6. & Some orphan learners appear lonely. & 4 & 15 & 27 \\
7. & Some orphan learners portray high hardness. & 3 & 15 & 20 \\
8. & Some orphan learners are highly tempered. & 6 & 15 & 40 \\
9. & Some orphan learners behave in a sickly manner. & 4 & 15 & 27 \\
10. & Some orphan learners fight others. & 5 & 15 & 33 \\
11. & Some orphan learners are rude. & 5 & 15 & 33 \\
\hline
\end{tabular}

Source: Primary data 2011

Table 4.11 reveals that many orphan learners undergo different behavioural changes. Behaviours like absent mindedness, truancy, stealing, high hardness and sickly behaviours critically affects the academic performance hence posing as big challenges in education of the orphans. According to the numbers all orphans in the zone have undergone behavioural change. It reveals that these learners should be handled in a special way because they have special needs as behaviour managements is concerned.

Table 4.12: Showing whether members of the community assist orphan learners

\begin{tabular}{|l|c|c|c|}
\hline \multicolumn{1}{|c|}{ Assistance } & Respondents & Out of & Percentage \\
\hline Provide food & 4 & 15 & 26.7 \\
\hline Provide clothing & 2 & 15 & 13.5 \\
\hline Provide security & 1 & 15 & 6.7 \\
\hline Provide shelter & 1 & 15 & 6.7 \\
\hline Other aid in education & 2 & 15 & 13.3 \\
\hline TOTAL & 10 & 75 & 13.3 \\
\hline
\end{tabular}

Source: Primary data 2011

Table 4.12 reveals that community members gives very little support towards the wellbeing of the orphan learners. This being an overall $13 \%$ is a low percentage. There might be lack of proper knowledge of the plight of these orphan learners. These orphans belongs to the community hence they should get maximum support from it. This will play part in increasing education challenges of orphan learners.

Table 4.13: Showing how members of the community assist these orphans

\begin{tabular}{|l|c|c|c|}
\hline \multicolumn{1}{|c|}{ Responses } & Respondents & Out of & Percentage (\%) \\
\hline Provide food & 5 & 15 & 33 \\
\hline Provide clothing & 2 & 15 & 13 \\
\hline Provide security & 1 & 15 & 7 \\
\hline Provide shelter & 1 & 15 & 7 \\
\hline Aid in education & 2 & 15 & 13 \\
\hline TOTAL & 11 & 75 & 14.6 \\
\hline
\end{tabular}

Source: Primary data 2011

Table 4.13 reveals that on average the members of the community where the orphans lives gives very little assists towards them. That is $14.6 \%$. Due to the many needs these orphans have, lack of assistance from the members of the community may pose educational challenges in them. It also indicated lack of enough knowledge about their occurrence 
in the community set up or ignorance on the side of community members about their occurrence.

Figure 4.10: Bar graph showing percentage assistance given by members of the community.

Source: Based on table 4.13

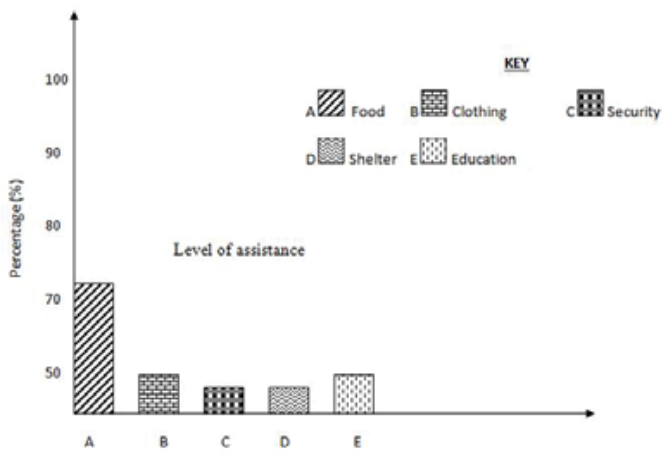

Table 4.14: Showing whether the school administration support education of orphan learners

Source: Primary data 2011

\begin{tabular}{|c|c|c|}
\hline Responses & Respondents & Percentage (\%) \\
\hline Yes & 12 & 80 \\
\hline No & 3 & 20 \\
\hline
\end{tabular}

Table 4.14 reveals that school administration in the zone supports orphan learners by $80 \%$. The administrators being the headteachers, chairman, treasurer and the deputy teacher supporting the education of orphans minimizes the many challenge that affect them in education. The school chairman and the treasurer being part of the parents body should take this good gesture to the parents to change their attitudes towards the plight of orphans in their neigbourhood. A margin of $20 \%$ of the school administrators do not support the learning of the orphans. Orphans who are found in the schools where administrators are not supportive face educational challenges.

Figure 4.11: Pie chart showing respondents percentage and degrees who says the school's administration supports or do not support learning of orphans.

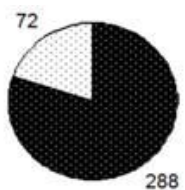

$80 \%$ (288) Supportive $\square 20 \%$ (72) unsupportive

Source: Based on table 4.14, page 60

Table 4.15: Showing whether there was any coordination between the educational assessment and resource centres and the school on the issue of assisting these learners

\begin{tabular}{|c|c|c|c|c|c|}
\hline \multirow{2}{*}{ School } & \multirow{2}{*}{ Respondents } & \multicolumn{2}{|c|}{ Responses } & \multicolumn{2}{c|}{ Percentage (\%) } \\
\cline { 3 - 6 } & & Yes & No & Yes & No \\
\hline Gachika & 3 & & 3 & & 20 \\
\hline Gathiru & 3 & & 3 & & 20 \\
\hline Gicheru & 3 & & 3 & & 20 \\
\hline Kiganjo & 3 & 1 & 2 & 6.7 & 13.3 \\
\hline Ecekeini & 3 & 2 & 1 & 13.3 & 6.7 \\
\hline TOTAL & 15 & 3 & 12 & 20 & 80 \\
\hline
\end{tabular}

Source: Primary data 2011 
Table 4.15 reveals that there is poor influence towards learning of orphan learners from the personnel of the Educational Assessment and Resource Centre (EARC). The 20\% responses reveals still there are some schools in the zone which gets assistance from the EARC. One possible explanation is that the officer manning these centres are fully aware of the existence of these learners in schools and have a duty to make their lives brightens day in, day out Orphans lacking this assistance may suffer educational challenges.

Table 4.16: Showing the guardian frequency of visits in school to follow the educational progress of orphans

\begin{tabular}{|l|c|c|c|}
\hline \multicolumn{1}{|c|}{ Response } & Respondents & Out of & Percentages (\%) \\
\hline More frequent & 3 & 15 & 20 \\
\hline Less frequent & 8 & 15 & 53 \\
\hline Never visited & 4 & 15 & 27 \\
\hline TOTAL & 15 & & 100 \\
\hline
\end{tabular}

Source: Primary data 2011

Table 4.15 reveals that many guardians do not follow keenly the educational progress of orphans. That is, above $50 \%$ are not interested in the progress of the education of orphans. Only $20 \%$ of the guardians frequently visited the schools where orphan learners were to follow their education progress. One of the major reasons with this behaviour portrayed by guardians would be the emotional sharing of orphans amongst relatives, siblings and other members of the community after the death of their parents without weighing the consequences and efforts of upbringing the orphan. This may cause educational challenges in the orphans.

Figure 4.13: Pie chart showing the percentage and in degrees rate of guardians frequency in visit schools where their orphans learns.

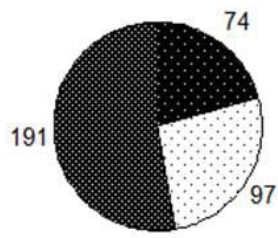

$20 \%(74)$ frequent visits

$\square 27 \%(97)$ never visited

$53 \%(191)$ less frequent visits

Source: Based on table 4.16, page 64

Table 4.17: Showing where majority of orphans end after ordinary level education

\begin{tabular}{|l|c|c|}
\hline \multicolumn{1}{|c|}{ Institution } & Respondents & Percentage (\%) \\
\hline Institutions of higher learning & 1 & 7 \\
\hline Vocational centres & 4 & 25 \\
\hline Casual labour & 9 & 60 \\
\hline Uncategorized & 1 & 8 \\
\hline TOTAL & 15 & 100 \\
\hline
\end{tabular}

Source: Primary data 2011

Table 4.17 reveals that many orphan learners end up in casual labour as $60 \%$ falls in this category. Those who pursue higher education is minimal. It seems these orphans are affected education wise during lower learning grades. This further implies that many orphan learners, that is $60 \%$ lead poor lives after school. If this trend is not diverted, a cycle of poverty and dependency will always recur. The eight percent uncategorized part of orphan learners implies that, they may be living in the underworld turning to be thieves, murderers or drug addicts. The seven percent representing orphan learners who join higher institutions of learning clearly sheds light on the many educational challenges faced by them. 
Figure 4.14: Pie chart showing percentage and in degree of respondents stating where orphan learners end after ordinary education.
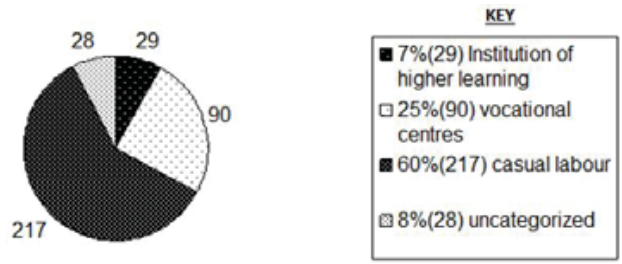

Source: Based on table 4.17, page 65

Table 4.18: Showing whether the government has generated funds for the orphan learners through the free $\frac{K E Y}{\text { primary }}$ education (FPE) fund.

Source: Primary data 2011

\begin{tabular}{|c|c|c|}
\hline Response & Respondents & Percentage (\%) \\
\hline Yes & - & 0 \\
\hline No & 5 & 100 \\
\hline
\end{tabular}

Table 4.18 reveals that the government had not generated funds especially for orphan learners through FPE Funds as $100 \%$ of respondents said "No". Many issues emerged after the inception of FPE. Such issues include shortages of teachers, lack of enough classes and improper curriculum coverage. To solve these problems, each school organizes ways of solving them. One of the major solutions is to share the cost amongst parents. Orphans are not left out. This poses serious educational challenges on the side of orphan learners as a lot of time is wasted on looking for ways of covering the levy.

Table 4.19: Showing whether there is a modified curriculum for orphan learners

\begin{tabular}{|c|c|c|}
\hline Response & Respondents & Percentage (\%) \\
\hline Yes & - & 0 \\
\hline No & 15 & 100 \\
\hline
\end{tabular}

Source: Primary data 2011

Table 4.19: Shows that no modified (special) curriculum prepared by the policy makers to cater for orphan learners. This means all learners are treated the same regardless of this special need of lack of parents. As the curriculum is the basic denominator in preparations and dissemination of knowledge by teachers, these leaves orphan learners unfairly catered for.

Table 4.20: Showing whether there are community based organizations (CBO) concerned with orphan education in the zone.

\begin{tabular}{|c|c|c|}
\hline Responses & Respondents & Percentage (\%) \\
\hline Yes & - & 0 \\
\hline No & 5 & 100 \\
\hline TOTAL & 5 & 100 \\
\hline
\end{tabular}

Source: Primary data 2011

Table 4.20 reveals that there lacks $\mathrm{CBO}$ as represented by $0 \%$. CBOs are helpful if available because they deal with known problems with people who know the problem. When members of a certain CBO meet, they discuss many issues concerning problems faced by different groups with special needs. As a matter of fact, they should discuss educational 
challenges of orphan learners. The CBOs should extend their wings in giving services in all zones in the country. Due to their knowledge of problems affecting people CBOs can be used to brow the whistle when problems run from bad to worse. As revealed by table 4.20, the area of Kiganjo zone lacks this valuable service hence posing serious educational challenges to the orphan learners of Kiganjo Zone.

Table 4.21: Showing whether the orphans benefit from constituency development fund (CDF) to pursue further education

\begin{tabular}{|c|c|c|}
\hline Responses & Respondents & Percentage (\%) \\
\hline Yes & 5 & 100 \\
\hline No & - & 0 \\
\hline TOTAL & 5 & 100 \\
\hline
\end{tabular}

Source: Primary data 2011

Table 4.21 reveals that CDF is fully utilized in educating orphan learners in the zone as represented by $100 \%$. This paints a brighter future for these learners who manage to enter secondary and even university education. All those concerned should help these orphans go beyond Kenya Certificate of Primary Education (KCPE). The educational challenges faced as an orphan undergoes primary education are the major handles to the world of prosperity of these learners.

\section{Recommendations}

The researcher noted that the presence of orphans in the community have been there since time immemorial. Secondly these orphans have been suffering together with their caregivers like the siblings, grandparents or even relatives while they get very little support from the government. It is the right of all children regardless of their status in the society to education, value, assurance of shelter and allowance to participate fully in the society. Orphan learners in Kiganjo Zone have been found to suffer psychologically, emotionally, economically and spiritually.

The following should be done to put back these orphans to situations as if their parents were alive. The government should allocate funds to start rehabilitation centres for orphans whose character and behaviour have been adversely affected. In the rehabilitation centre the orphan will be put back to the original state as much as possible. Later, these orphans can be put back to local schools. Presently, the rehabilitation centres are very few and are managed on charity basis. Due to difficult situations at the homes of the orphans, the government should start 'homes' for them at zonal levels. For example in Kiganjo zone one home for the orphans would help very much. In the home, they will share, get enough food, shelter and proper education. Where the government is unable to offer the services, Non-governmental Organizations would come in and help.

As it was found in the research findings, many members of the community target the existence of orphans after their parents dies. This means a lot of community awareness should be put in place. The Ministry of Information and Communication should be involved whereby awareness is done through the mass media. For example radios, newspapers and magazines. During meetings, elected leaders and politicians like members of parliament and councilors should emphasize on the presence and plight of these orphans. Also in churches and mosques, in youth gatherings and women come together, the issues of orphans should never be left out. The Ministry of Planning and attainment of Vision 2030 should include in their census questionnaire about the number of orphans found in every homestead. After the census, as a ministry, they would manage to see at a glance the total population of orphans in the country. The figures would help the government in planning for orphans at a range of ten years.

Orphans should not be shared emotionally immediately their parents die. As it was found in the research findings, these guardians later finds it burdensome hence leaving the orphans improperly attended. The guardians should first be counseled and guided on their future responsibilities to the orphans. The local children's office should have a department of guidance and counseling. These officers will guide both the orphans and the guardians to be. They should also help in calming the psychological effects on orphan learners which affects them after the death of their parents. This will help substitute the immediate loss of parental love and consequential take over by guardians purporting to give the same. After guidance and counseling, the caregivers and guardians of the orphans will manage to give parental protection hence minimizing misuse by relatives and others through hard labour, practicing sexual harassment and marrying them off before the minimum age.

The pilot project in some district in Kenya called cash transfer OVC (Orphans and Vulnerable Children) is from the 
government kitty. The money is given at district level. The government intention is to facilitate the wellbeing of these orphans. The procedure of issuing the money was found to be discriminatory. This is so because of the criteria they follow when selecting the orphans to benefit. One of the selection criteria was noted as, not in way the orphan is related to the committee members. The government should increase the money budgeted and all orphans below eighteen years should benefit. The government should also vet properly the guardians who receive the money on behalf of the orphans. Such proper vetting criteria would help eliminate greedy guardians and pretenders who do not have time for these orphans.

The headteachers and principals of primary and secondary schools respectively should have proper records of orphan learners in their institutions of learning. This will help them to identify the guardians and hence make them follow the orphans' educational progress. A joint effort by guardians and these teachers in following the educational progress of orphans would help in the long run in ensuring many of these learners join institutions of higher learning. The government should also cater for orphan learners by increasing the amount of money set side for Free Primary Education (FPE). This will put orphan learners in the category of special need learners. This will help the orphans to buy consumables like food and clothing. In the same line, a modified curriculum for these learners should be put in line with other learners with special needs in Kenya. The modified curriculum should be applied in rehabilitation centres and homes for orphan learners. It is also advisable for the Community Based Organizations (CBO) to extend their wings in giving services in all zones in the country.

Due to their knowledge of the problems affecting people, CBO's can be used to blow the whistle when problems run from bad to worse. The services of EARC coordinators which have been seen to have started coordinating issues of special needs in learners in the zone should be increased. These coordinators should target the learners, teachers and members of the public in guidance and counseling. It should be the duty of the government through the Ministry of Education to help in the education for all teachers in guidance and counseling and in special needs education. After the training, these teachers will acquire knowledge and skills to enable them handle orphans properly. The Ministry of Health $(\mathrm{MOH})$ should provide all types of drugs and other services in all hospitals and dispensaries. This would cater for the many medical problems found to affect these orphans.

\section{References}

Ainsworth, Martha, Kathleen Beagle and Godlike Koda 2007. "The impact of Adult mortality and parental deaths on primary schools in North -Western Zambia" Journal of Development studies 41 (3): 412-439

America Academy of Pediatric; (1961). Red Book. Report of the committee on the control of infectious Diseases, Evanston. Illinois.

Bond George C, (1997). Women, Children and AIDS, Boulder: Colorado. West view press http://www.nye2009 .org/projects/projects 3.php October 3, 2010

Hellmuth J. (1967). Disadvantaged child, Volume / New York. Brunner /Mazel Publishers.

Hellmuth J. (1978). Head start and early intervention, volume 2: New York. Brunner / Mazel Publishers.

Hellmuth J, (1999). Disadvantages child volume 3, compensatory education: a natural debate: New York. Brunner /Mazel publishers.

Orodho J. A., (2008). Techniques of writing research proposal \& reports in educational and social science: Maseno.Kanezja Publishers.

Orodho J. A., (2009). Elements of Education and social science Research methods: Maseno Kanezja publishers.

Lewis O, (1966). "The culture of poverty, scientific American, Volume 215. No.4" unpublished.

Nicole K, (2009). "Homebased on Jewish Principles to help Rwanda Genocide orphans." The Globe Mail Rss. 2.0 feed.

Wills R, (2009). The Aids pandemic; Lincol-shire England. The Stan borough press limited.

The Central digest Journal, January 31st, 2010

The Herald Magazine, July 2004

The Standard Newspaper. October 19, 2008

Theresa S, (2009). High Hopes, Grim Reality: Reintegration and the education for former child soldiers in Sierra Leone. Comp Edu, Rev. Author Manuscript.

UNICEF OVC Background paper on conditional cash subsidies for Children Affected by HIVIAIDS

Wortis T, (1963). A child rearing practices in low social economic group. Pediatrics, 32: 298 